\title{
O atendimento por instituição pública de saúde: percepção de famílias de doentes com câncer
}

Treatment by a public health care institution: from the perspective of the families of cancer patients

Juliana Stoppa Menezes Rodrigues', Ellen Cristine Ramdohr Sobrinho², Maria Luíza Vasco de Toledo³, Sonia Regina Zerbetto ${ }^{4}$, Noeli Marchioro Liston Andrade Ferreira ${ }^{5}$

1 Mestre em enfermagem pelo Programa de Pós-Graduação em Enfermagem da

Universidade Federal de São Carlos (UFSCar) - São Carlos (SP), Brasil.

julianasmrodrigues@bol.com.br

${ }^{2}$ Mestranda em enfermagem pelo Programa de Pós-Graduação em Enfermagem da

Universidade Federal de São Carlos (UFSCar)

- São Carlos (SP), Brasil.

ellem_ramdohr@yahoo.com.br

${ }^{3}$ Graduação em Enfermagem pela Faculdade de Medicina de São José do Rio Preto (FAMERP) - São José do Rio Preto (SP), Brasil.

Enfermeira assistencial da Universidade Estadual Paulista Júlio de Mesquita Filho (UNESP) - São Paulo (SP), Brasil.

malutoledo@gmail.com

${ }^{4}$ Professora Adjunta do Departamento de Enfermagem da Universidade Federal de São Carlos (UFSCar) - São Carlos (SP), Brasil. szerbetto@ufscar.br

${ }^{5}$ Professora Associada do Departamento de Enfermagem da Universidade Federal de São Carlos (UFSCar) - São Carlos (SP), Brasil. noeli@ufscar.br
RESUMO Este estudo objetivou analisar como as famílias de pessoas com câncer perceberam o atendimento prestado pelos profissionais de um ambulatório público especializado, utilizando Análise Temática de Bardin. Foram entrevistadas 7 famílias, totalizando 14 membros familiares que, em seus discursos, enfatizaram a relação médico-paciente, avaliando-a como impessoal e superficial, gerando insegurança e descrença. A família procura participar, mas sente-se pouco valorada e excluída do cuidado. As informações necessárias e não recebidas são buscadas na mídia, e o conforto é alcançado na espiritualidade. A formação dos diversos profissionais da saúde precisa estimular o olhar para a família como unidade de cuidado, articulando formação e modos de cuidar em saúde.

PALAVRAS CHAVE: Pessoal de saúde; neoplasias; família.

\begin{abstract}
This study aimed to analyze how the families of cancer patients perceived the treatment provided at a specialist public outpatient clinic, using Bardin's method of Content Analysis. Seven families consisting of fourteen family members were interviewed. They underlined doctor-patient relationship, judging it to be impersonal and superficial, resulting in a lack of security and trust. Families try to to participate but feel undervalued and excluded from the care. Necessary information that they are not given is sought in the media, while comfort is achieved through religious or spiritual practices. Health care training must encourage professionals to view the family as a unit of care, aligning training to different modes of health care.
\end{abstract}

KEYWORDS: Health Personnel; neoplasms; family. 


\section{Introdução}

O Sistema Único de Saúde (SUS) surge no Brasil em decorrência da luta pela democratização da saúde, a fim de aumentar a participação popular na gestão da saúde (LABRA, 2005). Sua regulamentação, por meio das Leis n. 8.080 e n. 8.142, busca consolidar os princípios de: universalidade de acesso em todos os níveis de assistência à saúde; integralidade, apreendida como ações preventivas e curativas, individuais e coletivas, em todos os níveis de complexidade e igualdade, sem privilégios ou preconceitos (LINARD et al, 2011).

Um grande desafio do SUS tem sido a garantia de assegurar ao cidadão a atenção integral de promoção, prevenção e tratamento, e a qualidade do processo de trabalho firmado em seus princípios, que deve ser garantida em todos os níveis de assistência (OLIVEIRA et al, 2011).

Para assegurar a qualidade da assistência nos três níveis, é fundamental que as relaçôes interpessoais (profissionais de saúde e famílias) priorizem o acolhimento como estratégia para apreender e atender às reais demandas dos usuários, buscando garantir a integralidade e a acessibilidade universal, além da reorganização do foco da assistência para uma equipe multipro $\neg$ fissional, ampliando a tradicional visão medicocentrista (TRINDADE et al, 2011).

Sabe-se que a família, hoje, precisa ser apreendida como uma unidade de cuidado a ser cuidada e que, no âmbito das doenças crônicas, como o câncer, por exemplo, o contexto familiar se torna um importante espaço de aporte à vida. Uma relação saudável entre os profissionais de saúde, usuários e famílias pode ser benéfica no enfrentamento da doença e de suas consequências, minimizando os anseios e medos que, inevitavelmente, permeiam esse contexto. Profissionais capacitados tornam-se aptos a identificar as reais necessidades dos usuários, entendendo o ambiente familiar como parte do cuidado (SIQUEIRA et al, 2006).

Críticas ao funcionamento do SUS (SIQUEIRA et al, 2006; TRINDADE et al, 2011) apontam que a qualidade dos cuidados de saúde (oferecidos no âmbito público) necessita ser fortalecida, e, sendo assim, conhecer o que a família pensa a respeito dos serviços é uma ferramenta importante para gestores, profissionais, pesquisadores e usuários.

Frente a isso, este estudo objetivou: analisar como as famílias de pessoas com câncer perceberam o atendimento prestado pelos profissionais do Sistema Único de Saúde.

\section{Metodologia}

Este é um estudo exploratório-descritivo, de cunho qualitativo, desenvolvido a partir da reanálise de entrevistas realizadas com famílias de doentes com câncer, atendidos pelo SUS, armazenadas no banco de dados do Grupo de Pesquisa Saúde e Família, cadastrado no CNPq, e aprovada pelo Comitê de Ética em Pesquisa da UFSCar (Processo no 218/2010). O banco de dados constituise numa importante ferramenta para a pesquisa porque possibilita a otimização das informaçóes, servindo de fonte para aprofundar e consolidar resultados.

Esse grupo, desde 2002, vem desenvolvendo pesquisas com famílias que possuem um membro familiar portador de doença crônica (idosos demenciados, transtornos mentais, câncer e situações crônicas da infância), utilizando diferentes abordagens metodológicas em cada projeto, dentro da linha de pesquisa: tecnologia do cuidado com famílias.

Para este trabalho, foram mantidos os mesmos critérios de inclusão originais, ou seja: entrevistas com famílias de doentes com câncer adultos, cadastrados em instituiçẫo pública de uma cidade do interior paulista, com diagnóstico confirmado por biópsia, em pleno tratamento da doença, em condiçóes de realizar a entrevista no domicílio, autorização da família e garantia de, pelo menos, uma díade familiar no momento da entrevista. Como critério de exclusão, tivemos: câncer infantil ou em adolescentes; óbitos no período da coleta; diagnóstico de câncer de pele não melanoma; abandono do tratamento no período; não possuir comprovação por biópsia ou a constatação diagnóstica inferior a um ano, objetivando obter um mínimo de experiência na relação terapêutica com os serviços públicos.

As entrevistas estavam transcritas na íntegra, eram do tipo abertas ou livres, em resposta à questáo 
norteadora: 'Os profissionais de saúde têm oferecido informaçōes sobre a doença, o tratamento, os cuidados, enfim, sobre tudo que a família precisa saber para prestar o cuidado?'. Percebeu-se que, a partir da questão norteadora, a temática sobre a qualidade do atendimento do SUS surgiu com muita relevância, suscitando a possibilidade de uma reanálise com esse enfoque. Todas foram relidas minuciosamente, com o propósito de destacar aquelas que traziam aspectos relacionais entre equipe e família, resultando em 7 entrevistas, perfazendo um total de 14 pessoas.

Optou-se pela Análise de Conteúdo Modalidade Temática proposta por Bardin (2009), definida como o conjunto de técnicas de análise das comunicações, que permitem analisar os significados (análise temática) ou significantes (análise lexical).

A Análise de Conteúdo Modalidade Temática de Bardin possui como alvo a superaçáo da incerteza, confirmando ou não o que se julga ver na mensagem. A leitura do material leva à validaçáo e à generalização dos dados, enriquecendo a leitura pela descoberta de conteúdos e estruturas que confirmam ou negam o que se procura demonstrar, a propósito das mensagens/elementos de significação (BARDIN, 2009).

Essa modalidade (BARDIN, 2009) utiliza a Regra da Representatividade nas etapas pré-análise; exploração do material com tratamento dos resultados obtidos e interpretação. Na Pré-análise, a leitura é flutuante e possibilita a formulação de objetivos e hipóteses iniciais que norteiam a interpretação final. $\mathrm{Na}$ Exploração do material, são realizadas: transcrição das falas; destaque das frases e das orações significativas; agregação das frases em temas e geração das categorias. Finalizando a análise, é feita a interpretação do conteúdo. A partir de procedimentos exploratórios, é possível apreender a ligação existente entre as diferentes variáveis e elaborar novas hipóteses.

\section{Resultados}

Dos 14 membros familiares, quatro eram doentes, do gênero masculino, com diagnóstico de neoplasia de próstata; e três doentes eram do gênero feminino, com neoplasia pulmonar, melanoma maligno e linfoma não Hodgkin. Os demais membros familiares entrevistados compreendiam cinco do gênero feminino (três esposas e duas filhas) e dois do gênero masculino (um esposo e um filho). A faixa etária dos participantes variou de 30 a 79 anos.

O trabalho de interpretação dos dados, segundo a metodologia proposta, permitiu elencar os temas representativos das falas que foram identificadas e nomeadas, formando as categorias de acordo com os seguintes significados apreendidos: 'Recebendo atendimento dos profissionais; Levando o familiar para ajudar a enfrentar o sistema; Percebendo a exclusão da família do cuidado; Desacreditando no sistema de saúde e nos profissionais; Suprindo as deficiências do sistema e buscando apoio para além do sistema'.

A seguir, serão apresentadas cada uma das categorias e as falas representativas que foram identificadas, com números arábicos representando a pertença familiar e o parentesco, a fim de respeitar o anonimato.

\section{Recebendo atendimento dos profissionais}

Uma das principais condiçóes para que se instale um vínculo de confiança é a sensação de segurança na assistência recebida, geralmente atrelada à competência técnica e atitudinal do profissional, pois, pela forma como se dá o atendimento ao cliente, este pode avaliar o serviço e, consequentemente, exercer julgamento sobre a capacitação do profissional que o atende. Embora as famílias tenham sido atendidas por uma equipe multidisciplinar, as falas representativas dessa categoria giraram espontaneamente em torno da consulta médica, e demonstraram situaçóes em que o usuário percebeu o descaso nesse atendimento.

Ah, eu chegava lá e ele [médico], num prazo de um minuto, já receitava o remédio. E foi assim. (...) (Doente - Família 1).

Eles [médicos] não têm paciência. Eles não consultam a gente, nem faz exame... dessa coisa, como é que chama? Pressão! Não faz nada, só olha e pronto. (Doente - Família 6). 
As famílias verbalizaram suas impressóes sobre a qualidade do atendimento recebido e, em algumas situaçóes, consideraram-no impessoal, fato que as fez sentirem-se desrespeitadas em seus direitos, levando-as a tomar a decisão de procurar outro profissional.

Tem alguns [médicos] estúpidos, né? Pra lidar com a gente. Às vezes, eles não dão a explicação certa e ai a gente fica que nem bobo pra lá e pra cá. (Esposa-Familia 1).

Complicou, e aí eu mudei até de médico. Nem examinava nada, não. Ai eu troquei de médico. (Doente - Família 4).

Os médicos, quando eles falam pra gente, a gente acredita no que ele tá falando, mas, ao mesmo tempo, fica em dúvida. Será que ele tá mentindo? (Doente - Família 5).

Todas essas percepçóes trouxeram sentimento de insegurança, sensação de estar perdido e o receio pela própria vida, que, quer queira ou não, está nas mãos daquele profissional.

Não pela hora... eu fiquei com medo, assim, porque, puxa vida, já me cortou e já vai cortar de novo. E depois, se mesmo assim ficar pior? (Doente - Família 5).

(...) até que eu achei que, com ele, se eu tivesse continuado, eu tinha morrido, né? (Doente Família 1).

Do jeito que tá aqui, não tem condição. (...) Você vai. Chega lá no Pronto Atendimento, tem dois, três médicos e cinquenta pessoas. (...) vai demorar pelo menos uma hora aqui. $\mathrm{O}$ outro lá [médico] vem aqui e pula direto, e 'mata' você. (Doente - Família 2).

Outro aspecto destacado nas falas foi o modelo de referência e contrarreferência As famílias ouvidas consideraram que esse modelo, adotado pelos serviços utilizados, apresentou falhas, pois os clientes que necessitaram ser encaminhados de um serviço para outro tiveram que passar por diversos departamentos, tendo que aguardar longos períodos para conseguir uma consulta, fechar diagnóstico, para, só então, serem encaminhados para o início da resolução do seu problema de saúde.

Mas, depois, ele me encaminhou pra uma máfia pra fazer a biópsia, sabe? Ai, daqui [UBS], ele mandou pro E [hospital]. O E mandou pro $Z$ ou $V$, não sei. E os vigaristas, pra falar a verdade, eles pediram diversas amostras da próstata, eles pediram lá 200 reais pra analisar cada parte. (Doente - Família 2).

Você chega a ir em três hospitais diferentes. Cada um deles vai agir de um modo, cada médico vai falar uma coisa. Então, a gente não tem um conhecimento pra discernir o que está certo, o que está errado. (Filha - Família 2).

\section{Levando o familiar para ajudar a enfrentar o sistema} A família é muito importante na relação profissionalpaciente, pois é com ela que o doente conta para enfrentar as demandas e consequências de seu próprio tratamento. Devido à complexidade das abordagens terapêuticas do câncer, na maioria das vezes, a família acompanha o doente nas consultas e nos procedimentos, a fim de ajudá-lo, sendo seu ponto de segurança, auxílio e alívio. Isso pode ser percebido através das seguintes falas:

Em todas as vezes que eu fui na operação, nos dias que fiquei lá, ela [esposa] ficou lá comigo... $e$, cada vez que vou, ela vai junto, nunca vou sozinho... Ai, ela ouvia tudo o que eu ouvia, porque ela entrava junto comigo... na operaçâo, ela foi até na porta, quase entrou lá dentro. (Doente-Família 1).

Eu cheguei a ir no hospital algumas vezes. Eu ficava lá, no horário de visita, pra gente tranquilizar ele. (Filha-Familia 2). 
(...) naquele dia, chamaram ela, e falaram e tal, falaram assim na lata: "a senhora está com um tumor maligno", e eu junto. (Esposo - Familia 3).

\section{Percebendo a exclusão da família do cuidado}

A família se constitui por ser a principal instituição social na qual o indivíduo inicia e cria suas relações afetivas e interacionais, buscando estabelecer conexóes e vínculos entre seus membros (ARAUJO; NASCIMENTO, 2004). Sendo assim, quando algum membro da família sofre de uma doença grave, logo, toda a sua estrutura familiar é afetada, sofrendo modificaçóes e adaptações ao seu novo modo de vida.

Em uma situação de câncer dentro do seio familiar é praticamente inevitável o envolvimento familiar, já que essa é uma das principais fontes de apoio para o enfrentamento da doença e de suas consequências. Os profissionais de saúde precisam ser participantes desse processo, apropriando-se de recursos para promoção do cuidado da unidade familiar, de modo a facilitar o tratamento e contribuir para o fortalecimento da condição emocional do doente. No entanto, em suas falas, a família demonstra náo encontrar nos profissionais de saúde essa compreensão.

Porque, como eles [os médicos] não conversam com a gente [familia], quando a gente queria saber o que tinha acontecido com ele [doente], como é que tinha sido, é a visão dele, né?(...). Mas, assim... eu cheguei a ir no hospital algumas vezes, mas lá é muito movimento, é muita gente. Então, o contato principal com o médico ou quem precisava era diretamente com ele [doente]. (Filha-Familia 2).

(...) ela [a filha] ia junto, ouvia também, mas nada de atenção, não (...). (Doente - Família 4).

A família sente que alguns profissionais ainda não a veem como colaboradora no tratamento, pois não passam as informaçóes necessárias para que a continuidade do cuidado no domicílio aconteça de forma adequada. Essa percepção pode ser comprovada através da fala, que reflete a vivência de um membro familiar:

O médico está mais voltado pro paciente do que com a própria família. E o paciente tem que ter os cuidados. Mas eu acho que a familia também precisa muito de amparo. Porque depois, quando o paciente volta pra casa, é a gente que está junto com ele. Então, às vezes, se a gente tivesse noção de algumas coisas, quando ele está aqui e acontece alguma coisa, a gente sabe um pouco mais como agir, né? Então, talvez, se a gente tivesse tido um diálogo com essas pessoas [profissionais], a gente podia ver algumas coisas e entender um pouco mais, né? (Filha - Família 2).

Os entrevistados consideram ser importante que a família também possa obter maiores informações e explicações dos profissionais para poder lidar com os seus entes doentes no domicílio e durante as situaçôes vividas com a doença.

Mas, ah, é aquela explicação normal, como acompanhante: "tem que fazer isso, tem que fazer aquilo." (...) mas nada de atenção, não. Chamar ela [filha] pra conversar, não! (Doente-Família 4).

(...) acho que ele [médico] tinha que falar mais com a minha esposa [referindo-se às tentativas da esposa de acompanhá-lo], mas ela não foi lá porque, cada vez que eu ia, eu [só podia] ir sozinho. (...) Eu acho que, pra mim, ele falou certo. Agora, acho que tinha que falar mais pra minha esposa. (Doente - Família 5).

Não que a gente possa socorrer, mas você pode se sentir mais seguro ou entender o que está acontecendo. (Filha-Familia 2). 
Desacreditando no Sistema de Saúde e nos Profissionais A confiança naquele que vai prestar o cuidado é um fator importante quando se pensa em qualidade de assistência. Espera-se que o sistema de saúde seja capaz de suprir as demandas do cliente, que tem como expectativa um atendimento humanizado e resolutivo. Porém, nem sempre a família encontra o apoio ou o suporte que espera dos serviços e dos profissionais que atuam na área, como exemplificam as falas:

Então, a gente nunca sabe, de verdade, o que o médico tem a dizer (...) a família fica muito de mãos atadas (...). E, pra a gente, isso é desesperador, porque a familia sofre tanto quanto o paciente. Não tem a dor e tudo, mas sofre tanto quanto. (Filha-Familia 2).

Pra mim, eu não tive explicação, tanto pelo médico quanto pela enfermeira. Nâo tive nada, não. Não tive explicação nenhuma. (DoenteFamilia 4).

Quando eu fui prestar atenção naqueles prospectos que eu assinei, eu não fui ler aquilo. Eles [os médicos] explicam, mas não que você está correndo risco. (Doente - Família 2).

Nem perguntava por que eu falava assim. Você sabe como é médico do SUS, né? A gente chegava lá, ele só olhava e já mandava embora. Não falava nada. (Doente - Família 6).

A gente fica sem saber as limitaçôes. Às vezes, ele falava que ia fazer alguma coisa e a gente não tem noção se a gente devia falar 'não, não faça' ou se 'pode ir que não vai ter problema'. A gente fica sem saber, e a gente fica bem de mãos atadas mesmo. Acho que é essa a sensação que dá, assim, de impotência. (Filha - Familia 2).

\section{Suprindo as deficiências do Sistema}

Frente à necessidade de saber mais sobre a situação de saúde, sobre a doença e as possibilidades de tratamento, a família fica atenta a toda possibilidade de obter a informação almejada em todos os ambientes de saúde frequentados.

Fui na sala tomar quimioterapia... e as enfermeiras, toda vez que eu ia tomar, a gente tem até um livrinho, pra entender tudo o que eu devia fazer e o que eu não devia. (DoenteFamília 6).

No primeiro dia da quimioterapia, a nutricionista conversou bastante com a gente. Comigo, até deu um livrinho, que eu dei pra uma pessoa ler e até hoje não me devolveu. (Doente-Familia 7).

Quando não ocorre o esclarecimento desejado, nos contatos com os ambientes de tratamento, a família busca alternativas para suprir a lacuna que foi deixada pelos profissionais de saúde.

Uma coisa que eu acho que hoje ajuda, apesar de não ser a fonte mais confiável do mundo, é a internet, né? Ela é bem explicativa, você encontra opinióes de várias pessoas. A gente tem essa facilidade de poder acessar. (FilhaFamilia 2).

Eu tenho que ir lá na rede do câncer, ainda, e eles, de vez em quando, dão uma passada aqui pra ver. Eu acompanho muito a televisão. Quando o médico fala, eu já sei. Eu vejo passar na televisáo e já falo pros médicos que tudo isso aí eu já sei como é que é. (Doente - Família 3).

Teve aquele mutirão. Só homem que foi fazer exame, de próstata (...) Eu fui também lá no posto, entrei junto também. O homem [médico] estava fazendo. Eu falei: "Vou fazer também". (Doente - Família 5).

A gente sempre pegava um panfleto da doença pra tentar saber de alguma coisa mais, quando você vai nos consultórios médicos que tem 
aqueles panfletos. Agora, contato com os pro-

fissionais mesmo, é muito complicado. (Filha - Família 2).

\section{Buscando apoio para além do sistema}

Ao enfrentar uma situação de câncer, o principal objetivo da pessoa é encontrar a cura para a doença. A busca da cura pode acontecer por diversos caminhos. Quando a cura deixa de ser centrada apenas na medicina e em suas técnicas, há uma busca de outros recursos que supram essa necessidade. Para alguns dos entrevistados, a solução está associada à religiosidade/espiritualidade, na qual a fé conduz a creditar todo o sucesso do tratamento a um Ser Superior (Deus), independente do tipo de tratamento ou dos profissionais envolvidos nesse sucesso terapêutico.

Épor Deus! (...) A gente deu graças a Deus que ele ficou bom, né? (...) Tem coisa que a gente, sei lá, vê Deus. Só dele tá vivo, é ... Porque como ele estava... (Esposa-Família 1).

Eu sei que o tratamento foi bome, graças a Deus, eu creio que eu sarei. (Doente - Família 7).

Eu disse: "Não é sorte Dra, é Deus!" [referindose ao fato de ter um câncer de pulmão severo há cinco anos e ainda estar viva] (DoenteFamília 6).

O médico disse: "O senhor não tem mais nada!". Da até um alivio, graças a Deus. Nossa! E Deus foi tão bondoso que não esparramou pra lugar nenhum. Quer dizer, tirou inteiro. (Doente-Familia 3).

\section{Discussão}

Foram analisadas sete entrevistas realizadas com famílias de pessoas com diagnóstico de câncer. A Análise de Discurso Modalidade Temática de Bardin permitiu identificar os significados atribuídos à experiência da família, vivenciada durante o atendimento de seu familiar pelo SUS, e que foi concretizada em cinco categorias temáticas.

Em 'Recebendo atendimento dos Profissionais', as famílias trouxeram sua percepção frente à assistência e à atenção que receberam dos serviços, e, voluntariamente, destacaram, em suas falas, a relação médico-paciente. A confiança e a segurança no atendimento recebido se atrelam à competência e à resolutividade. Nesse caso, as famílias verbalizam sua impressão de desumanização e de desrespeito durante a assistência, o que traz um sentimento de insegurança e receio pela própria vida, já que sabe que aquele profissional está tomando decisões que irão definir seu destino.

Sabe-se que a resolutividade na atenção à saúde está associada ao recurso instrumental e ao conhecimento técnico dos profissionais, bem como à ação acolhedora, ao vínculo que se estabelece com o usuário, ao significado que se dá à relação profissional-usuário, que sugere o encontro de sujeitos com o sentido de atuar sobre o campo da saúde e proporcionar satisfação ao usuário, que, por sua vez, percebe sua necessidade atendida (FRANCO; MAGALHÁES, 2007).

Estudo desenvolvido para analisar a resolutividade do Sistema de Saúde mostra que esse tipo de avaliação depende de vários aspectos e, também, do olhar de quem está sendo pesquisado. Na visão dos usuários, por exemplo, um sistema eficiente é aquele que atende à demanda da população e que possui um modelo de referência e contrarreferência articulado de forma a encaminhá-los de maneira rápida para a solução do seu problema (TURRINI; LEBRÃO; CÉSAR, 2008). Contudo, outro estudo aponta que isso nem sempre acontece no dia a dia do serviço público. Obstáculos, como a demora em conseguir encaminhamento especializado, lentidão no fechamento correto do diagnóstico e demora para o início do tratamento, são situaçóes comumente vividas quando o sistema é procurado (ROSA; PELEGRINI; LIMA, 2011).

Os usuários destacaram, também, em um estudo avaliativo sobre acesso e acolhimento realizado em três capitais brasileiras, que em Unidades de Saúde da Família há dificuldades de acesso a exames, demora por atendimento na unidade e na consulta com especialistas, falta de medicamentos na farmácia, descontentamento 
com a forma de agendamento e insatisfação com o acolhimento na recepção (SOUZA et al, 2008).

Todo esse processo é, ainda, acompanhado pela falta de informação com relação à própria doença e ao tratamento. Os profissionais de saúde preocupam-se com o atendimento imediato do paciente, pouco valorizando as orientaçóes que devem ser dadas para que o tratamento tenha continuidade e a família tenha segurança em prestar os cuidados necessários no domicílio (RODRIGUES; FERREIRA, 2011).

As famílias ouvidas por nós enfatizaram suas críticas em torno da relaçáo médico-paciente, e, mesmo percebendo que, às vezes, a falha vem do sistema, sobrecarregando os profissionais, acabam sentindo insegurança e medo. Como forma de fortalecimento, as falas representativas de 'Levando o familiar para ajudar a enfrentar o sistema' mostram a necessidade dos doentes de ter o acompanhamento do seu familiar para garantir, talvez, uma melhor compreensão do processo terapêutico ou para receber orientaçóes sobre o cuidado que deverá manter no domicílio. Um trabalho realizado na radioterapia enfatiza que a presença da família é imprescindível, pois mostra ao doente que ele não está sozinho nessa jornada, já que os membros familiares estarão sempre com ele, interagindo e encorajando-o (ALMEIDA; PEREIRA; OLIVEIRA, 2008).

Mesmo sendo a família referenciada como principal instituição social, cuja estrutura pode promover apoio nas situações de agravos, como o câncer, foi possível identificar que, na temática 'Percebendo a exclusão da família do cuidado', muitas famílias não se sentem acolhidas e valorizadas pelos profissionais de saúde para participar ativamente do cuidado. Em contrapartida, um estudo realizado com o objetivo de analisar as percepçóes e dificuldades enfrentadas pelos médicos de um serviço público, no convívio com pacientes oncológicos, mostrou que a maioria deles percebe a família como uma forte ferramenta na relação com o paciente, minimizando as dificuldades e ajudando a estabelecer uma melhor relação de confiança entre médico e paciente (SILVA et al, 2011).

Outro estudo (BARROS; LOPES, 2007) reafirma a importância dada à informação adequada e de qualidade oferecida, principalmente, pelo profissional médico, tanto ao doente com câncer quanto aos seus familiares. Essas informaçóes foram consideradas úteis tanto para a manutenção do tratamento como para a continuidade do apoio familiar, sendo, particularmente, importante durante a revelação do diagnóstico de câncer.

A expectativa da família envolve receber dos profissionais de saúde cuidado humanizado, associado ao desempenho técnico de qualidade, de forma a suprir as demandas do seu membro familiar doente. Contudo, as falas apontam que a família percebe-se 'Desacreditando no Sistema de Saúde e nos Profissionais', pois não obtêm as respostas às suas dúvidas ou resolução para seus problemas.

De acordo com Pasche (2010), a questão da humanização da saúde tem se expressado de maneiras diversas, e se concretiza, principalmente, pela pouca responsabilização e pela descontinuidade do cuidado e dos tratamentos, levando os usuários do SUS a perguntar: quem cuida de quem? Quem me cuida? Com quem eu conto?

Como forma de suprir essa necessidade, a família recorre a outros meios de enfrentamento, com açóes que seguem 'Suprindo as deficiências do Sistema'. A internet tem sido, atualmente, o meio de comunicação mais procurado para suprir as dúvidas. Entretanto, como se sabe, esse meio nem sempre está disponível para todos e, quando não utilizado com cautela, pode também causar maior preocupação, confundindo as informações recebidas do profissional e aquelas encontradas na mídia.

Da mesma forma, a religiáo e a crença em Deus foi apontada pelos entrevistados como uma estratégia recorrente para enfrentar a situação de insegurança vivida durante o tratamento do câncer, trazendo significados de vida tanto para o doente quanto para seus familiares, sendo uma importante fonte de apoio, confirmada pelas falas representativas em 'Buscando apoio para além do sistema'.

Pesquisas apontam que os doentes de câncer buscam acreditar em algo ou alguém, a fim de superarem os enormes desafios advindos do tratamento, enfrentando dificuldades por meio da fé e se apegando à religiosidade para encarar as adversidades 
(LEWIS et al, 2005; LEWIS; COOPER; GUNAWARDENA, 2006). Isso pode ser demonstrado, também, pelo estudo de Almeida, Pereira e Oliveira, que comprova a forte influência da religiosidade em todas as fases do tratamento do câncer cérvico-uterino.

A crença em Deus como estratégia de enfrentamento da doença, muitas vezes, acaba influenciando pessoas da família a buscar a religiosidade, tornandoas mais reflexivas. Suas crenças religiosas (OLIVEIRA; FERNANDES; GALVÃO, 2005) passam a representar um dos principais suportes e apoios no enfrentamento da doença e de suas complicaçóes, proporcionando conforto e trazendo segurança para o doente e seus familiares, diante das incertezas do tratamento.

Apesar dos familiares apontarem necessidade de investimento e mudanças no âmbito microssocial, ou seja, nas interaçóes sociais entre os trabalhadores de saúde, usuários e seus familiares, no cotidiano do trabalho, outros fatores de maior complexidade e amplitude podem permear esse espaço. Percebe-se que conflitos ideológicos, interesses políticos, políticas de saúde e trabalhistas, condiçóes objetivas e subjetivas de trabalho, bem como a organização do sistema de saúde podem influenciar o modelo de atenção e gestão do SUS.

Dessa maneira, para superar tais obstáculos, necessita-se que tanto os usuários e seus familiares quanto trabalhadores de saúde e gestores assumam papéis de protagonistas nessa transformação, com posturas de autonomia e corresponsabilidade entre eles, possibilitando estabelecer vínculos e uma participação coletiva no processo de gestão (BRASIL, 2004). Para obter tais conquistas, algumas estratégias podem ser traçadas no âmbito da gestão municipal, como, por exemplo, implementação de plano de educação permanente para os trabalhadores de saúde, que aborde temas de humanização (capacitando-os para uma escuta qualificada), e treino na apreensão das necessidades de saúde das pessoas que buscam ajuda nos serviços públicos, instrumentalizando-as durante o desenvolvimento de práticas resolutivas de saúde para a população.

\section{Considerações Finais}

A preocupação constante de assegurar qualidade na assistência a famílias de doentes com câncer levou-nos a investigar a percepção dessas famílias sobre o atendimento oferecido pelos profissionais do Sistema Único de Saúde.

Apesar de as famílias estarem sendo atendidas por uma equipe multidisciplinar, os resultados apontam predomínio do modelo biomédico, uma vez que os entrevistados deram ênfase à consulta médica. Esse fato nos leva a questionar a real participação da equipe multidisciplinar no cuidado com a família. Consideramos que ou o cuidado dos demais profissionais não está sendo percebido pela família ou esse cuidado não está sendo valorizado por ela.

Como forma de reforço para o que considera insatisfatório, a pessoa com câncer busca levar seu familiar como uma oportunidade de dispor de mais um recurso para se orientar no cuidado e suprir as carências de informações. Porém, também a família não se sente acolhida como gostaria, julgando-se excluída do cuidado. As informações necessárias e não recebidas durante o atendimento são buscadas na mídia, com todos os riscos que isso pode acarretar, enquanto o conforto é alcançado através da religiosidade/espiritualidade.

No Brasil, o Sistema Único de Saúde (SUS), por meio da Estratégia de Saúde da Família (ESF), tem buscado melhorar a qualidade da assistência às famílias, deslocando o cuidado para uma equipe multiprofissional e para o lócus familiar. A criação de vínculos entre famílias e profissionais, estabelecidos por meio da visita domiciliária, permite conhecer o contexto onde a família está inserida, bem como trabalhar as reais necessidades e potencialidades das mesmas. Ademais, tais vínculos permitem que os problemas elencados pelas famílias como proeminentes sejam atendidos, sem que necessitem buscar, aleatoriamente e incessantemente, ajuda.

O Ministério da Saúde (MS) tem se empenhado nesse âmbito, propondo, por meio do programa HumanizaSUS, a humanização como norteadora da atenção e gestão nas instâncias do SUS, colocando em prática o conceito de humanizar, articulando tecnologia 
e acolhimento. Os profissionais de saúde inseridos nos serviços são importantes viabilizadores do encontro das famílias com as redes sociais, interligando pessoas com vínculos sociais comuns e permitindo que os recursos de apoio sejam otimizados. O câncer é uma doença associada a desequilíbrios na unidade familiar, e o suporte mútuo é essencial para que os recursos físicos e emocionais sejam complementados.

As constataçôes nos sugerem que ainda há uma grande distância para que o atendimento às reais demandas dos usuários seja garantido, visando à integralidade e à acessibilidade universal. Acredita-se que, para apreender e atender a esses princípios, seja necessário olhar para a interface formação profissional e modos de cuidar e gerir no SUS, com um maior investimento na formação dos profissionais da saúde, levando-os a adotar postura aberta e acolhedora como estratégia para apreender e se aproximar da família, considerando-a como unidade de cuidado e facilitando, assim, o atendimento de suas reais necessidade, ao mesmo tempo em que possibilita uma abertura para o diálogo e para intervençóes profissionais efetivas com as famílias.

$\mathrm{O}$ fato das entrevistas terem sido realizadas com famílias restritas a apenas um município, embora tenha sua validade, pode trazer limites ao estudo. A experiência de famílias em outras situações e contextos pode contribuir para exploraçôes acerca das interaçôes entre famílias e profissionais, que levem a um maior conhecimento e compreensão, permitindo intervenções de acordo com as demandas de cada família, em particular.

\section{Referências}

ALMEIDA, L.H.B.; PEREIRA, Y.B.A.S.; OLIVEIRA, T.A. Radioterapia: percepção de mulheres com câncer cérvico-uterino. Revista Brasileira de Enfermagem, Brasília, v.61, n.4, p.482-487, 2008.

BARDIN, L. Análise de Conteúdo. 5. ed. Lisboa: Edições 70, 2009. 281 p.

BARROS, D.O.; LOPES, R.L.M. Mulheres com câncer invasivo do colo uterino: suporte familiar como auxílio. Revista Brasileira de Enfermagem, Brasília, v.60, n.3, p.295-298, 2007.

BRASIL. Ministério da Saúde. Secretaria Executiva. Documento base para Gestores e Trabalhadores do SUS. Brasília: Ministério da Saúde, 2004.

FRANCO, T.B.; MAGALHÃES JUNIOR, H.M. Integralidade na assistência à saúde: a organização das linhas do cuidado. In: MERHY, E.E. et al (orgs). Trabalho em saúde: olhando e experienciando o SUS no cotidiano. 4. ed. São Paulo: Hucitec, 2007.

LABRA, M.E. Conselhos de Saúde: dilemas, avanços e desafios. In: LIMA, N.T.; GERSCHMAN, S.; ELDER, F.C. Saúde e democracia. Rio de Janeiro: FIOCRUZ, 2005.

LEWIS, D.; COOPER, J.; GUNAWARDENA, S. Caring Connection: Internet resources for family caregivers of children with cancer. In: ANNUAL Symposium Proceedings. Washington: American Medical Informatics Association, 2006. p. 1007.

LEWIS, D. et al. Caring Connection: developing an Internet resource for family caregivers of children with cancer. In: ANNUAL
Symposium Proceedings. Washington: American Medical Informatics Association, 2005. p.1026

LINARD, A.G. et al. Princípios do Sistema Único de Saúde: compreensão dos enfermeiros da Estratégia de Saúde da Família. Revista Gaúcha de Enfermagem, Porto Alegre, v.32, n.1, p.114-120, 2011.

OLIVEIRA, M.M. et al. Avaliação de processo do programa Saúde da Família: a sustentação da aceitabilidade. Revista de Enfermagem e Saúde, Pelotas, v.1, n.1, p. 14-23, 2011.

OLIVEIRA, M.S.; FERNANDES, A.F.C.; GALVÃO, M.T.G. Mulheres vivenciando o adoecer em face do câncer cérvico-uterino. Acta Paulista de Enfermagem, São Paulo, v.18, n.2, p.150-155, 2005.

PASCHE, D. F. Humanizar a formação para humanizar o SUS. Política Nacional de Humanização. Cadernos Humanizasus. Brasília: Ministério da Saúde, 2010. p. 63-72. v.1.

ROSA, R.B.; PELEGRINI, A.H.W.; LIMA, M.A.D.S. Resolutividade da assistência e satisfação de usuários da Estratégia Saúde da Família. Revista Gaúcha de Enfermagem, Porto Alegre, v.32, n.2, p.345-351, 2011

SILVA, C.M.G.H.C.et al. Relação médico-paciente em oncologia: medos, angústias e habilidades comunicacionais de médicos na cidade de Fortaleza (CE). Ciência e Saúde Coletiva, Rio de Janeiro, v.16, p.S1457-1465, 2011. 
SIQUEIRA, A.B. et al. Relacionamento enfermeiro, paciente e família: fatores comportamentais associados à qualidade da assistência. Arquivos Médicos do ABC, Santo André, v.31, n.2, p.73$77,2006$.

SOUZA, E.C.F. et al. Acesso e acolhimento na atenção básica: uma ánalise da percepção dos usuários e profissionais de saúde. Cadernos de Saúde Pública, São Paulo, v.24, p. S100-110, 2008.
TRINDADE, L.L. et al. Reflexões acerca do perfil de atendimento na estratégia saúde da família. Cogitare Enfermagem, Curitiba, v.16, n.1, p.162-166, 2011.

TURRINI, R.N.T.; LEBRÃO, M.L.; CESAR, C.L.G. Resolutividade dos serviços de saúde por inquérito domiciliar: percepção do usuário. Cadernos de Saúde Pública, São Paulo, v.24, n.3, p.663-674, 2008.

Recebido para publicação em Abril/2012

Versão final em Maio/2013

Conflito de interesse: não houve

Suporte financeiro: inexistente 